\title{
SEA SURFACE TEMPERATURES AT MILLPORT
}

\author{
By H. BARNeS \\ The Marine Station, Millport, Scotland
}

Sea surface temperatures have been taken daily at Keppel Pier, Millport $\left(55^{\circ} 44^{\prime} 55^{\prime \prime} \mathrm{N}\right.$. lat.; $4^{\circ} 54^{\prime} 20^{\prime \prime} \mathrm{W}$. long.), for the past Io years (1949-58), the data being included in returns to the Meteorological Office. The records are not given in their standard publication and they are, therefore, presented here to supplement those of Cooper (1958) for inshore waters at Plymouth some 400 miles farther to the south. For some years the samples were drawn in a specially constructed container fitted with a Fahrenheit thermometer which was read to the nearest whole degree; more recently the bucket method has been used, and a centigrade thermometer graduated in degrees and read to an estimated tenth of a degree. The two methods were checked against each other before the change was made and the results found to be consistent. All readings were taken at $09.00 \mathrm{~h}$ G.M.T., irrespective of the state of the tide. The results are shown in Table $\mathrm{I}$.

The form of the annual temperature regime is typical of boreal waters; there are, however, considerable variations from year to year, not only in the mean values but also in the temperature pattern and these variations are of ecological significance. For example, in a long cold spring the spawning of some species is delayed. In some years the temperature, after falling steadily during the autumn and winter, remains almost constant from January to April; e.g. in 1952 and 1953 when the value remained close to $7^{\circ} \mathrm{C}$. during these months. In other years the temperature continues to fall during the early part of the year; in 1956, for example, this fall continued until late March, whereas in 1949 the temperature began to rise gradually in early March. In both I 954 and 1955 the temperature fell until early February, but whereas in 1954 this was followed by a slow rise, in 1955 the minimum was maintained throughout March. In I950 the minimum was reached late in January.

Apart from day-to-day fluctuations due to local heating in shallow waters there are also, during the summer, periods of low temperature extending over 2-3 weeks; these may be the result of up-welling in the deeper basins and could be of considerable importance in the destruction of warmer water species carried into the area during the warmer months of the year.

\section{REFERENCE}

Cooper, L. H. N., 1958. Sea temperatures in Plymouth Sound. F. mar. biol. Ass. U.K., Vol. 37, pp. I-3. 
TABLE 1. MEAN MONTHLY SEA SURFACE TEMPERATURES $\left({ }^{\circ}\right.$ C.) FOR MILLPORT, 1949-58, TOGETHER WITH MAXIMA AND MINIMA ATTAINED IN EACH MONTH

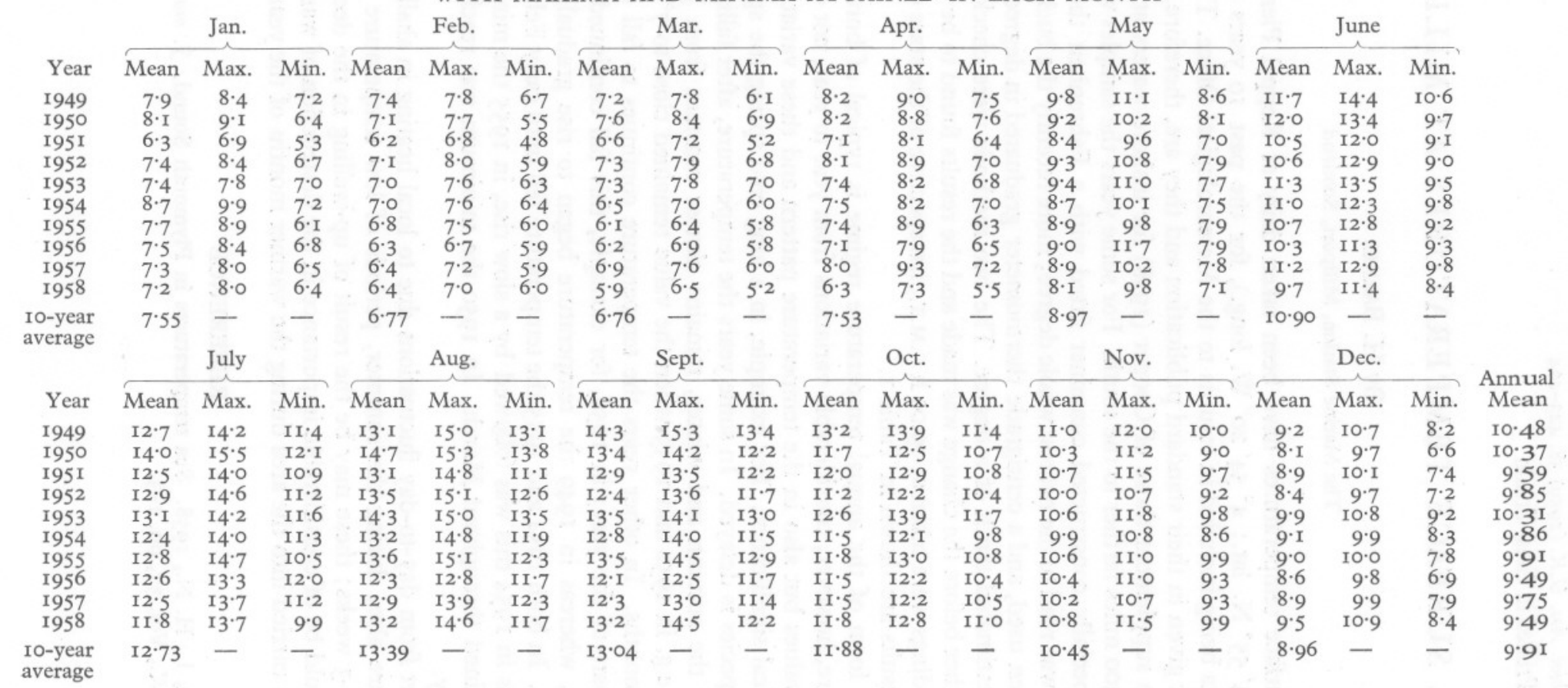

